\title{
Using 30 Years of Institutional Data to Discover Critical Trends Among Freshmen
}

\author{
Casandra E. Harper, Jennifer R. Keup, and Beth Brewer
}

Each year colleges and universities across the country are flooded with new students at orientation and welcome week. These students come from "diverse backgrounds, went through different secondary school environments and experiences, have varying levels of academic preparation, and seek different types of college experiences" (Keup, 2004, p. 8). As we welcome our new cohorts of students at our institution and assist them through their transition to college, we are challenged to understand them on both an individual and collective level in order to provide services and programs that suit their needs and facilitate the fulfillment of their goals in college and beyond (Coomes \& DeBard, 2004).

A simple assessment of incoming students' background characteristics, and personal histories, expectations, and aspirations, is the most common and effective means to capture information and represents the first step of a comprehensive model for assessing first-year students (Crissman \& Upcraft, 2001; Upcraft, 2005). These data collected from our new students allow an institution to create a comprehensive profile of the incoming cohort, which provides a descriptive story that may be used "to educate faculty, staff, students, and many interested external constituents about the nature of our student population" (Hansen \& Denzine, 2000, p. 6). When we use these data to answer the question "Who are our students?" we become better equipped to summarize their preparation for the academic rigors of college, identify critical areas of need and interest, and recognize potential points for advisement and intervention (Hansen \& Denzine, 2000; Keup \& Kinzie, 2007; Swing, 2004). Further, when we collect data from our incoming cohort of students, the gathered information can often have broader policy implications for the campus, including helping "colleges to determine their impact on student recruitment, student development, and student retention and career preparation" (Pryor, Hurtado, Saenz, Santos, \& Korn, 2007, p. viii).

One of the most commonly used instruments for this baseline assessment is the Cooperative Institutional Research Program (CIRP) Freshman Survey, which is used by hundreds of colleges nationwide each year to collect a wide array of information on students' academic, social, and personal experiences and identity (Astin, 2003; Pryor, Hurtado, Saenz, Santos, et al., 2007; Pryor, Hurtado, Saenz,

Casandra E. Harper (charper@saonet.ucla.edu) is the Principal Research Analyst in the Student Affairs Information \& Research Office at UCLA, Jennifer R. Keup (jkeup@saonet.ucla.edu) is the Director of the Student Affairs Information \& Research Office at UCLA, and Beth Brewer (bbrewer@saonet.ucla.edu) is an Administrative Analyst in the Student Affairs Information \& Research Office at UCLA. 
Korn, et al., 2006). While this instrument is comprehensive in nature in any single year, one of the additional benefits of consistent administration of the Freshman Survey is the collection of common data across cohorts of entering students. Multi-year data add significant value by facilitating the comparison of information across cohorts and allowing for the assessment of trends over time (Astin, 2003; Coomes \& DeBard, 2004; Pryor, Hurtado, Saenz, Santos, et al., 2007).

Such comparisons of cohorts of new students over time broaden the vista of possibilities for baseline data collected each year. Campuses often draw upon these data at significant points in time when a historical context is especially useful or of great impact, such as on anniversaries, during transitions in leadership, or to support accreditation activities. However, utilization of trends data is important, not just because of what it can tell us about our past, but for what it suggests about our future. In other words, the use of these data allows faculty, academic administrators, and student affairs professionals to contextualize the profile of any one cohort in the larger scheme of who our students were in the past and the directions that our future cohorts might be heading with respect to personal characteristics, experiences, and beliefs. This ability to predict and project the characteristics and needs of our students in an empirically informed fashion affords higher education institutions the opportunity to be strategic and proactive in their use of pedagogy, offering of programs, and development of policy.

Further, the relatively recent emphasis on a generational paradigm for understanding social, political, and educational issues as well as shifts in popular culture has made trends data even more useful to our understanding of students and the college experience. According to those scholars who use generational analyses to understand higher education, it is critical for us to understand not only the current generation of students but also "its interactions with other extant generations" (Coomes \& DeBard, 2004, p. 8; also see Strauss \& Howe, 1991). Further, given the way that generations are defined, we have recently witnessed a significant shift in generations by welcoming the first cohorts of the "Millennial" students onto our campuses (i.e., those who were born between 1982 and 2002), which represent the largest and most diverse group of incoming students in our nation's history (Coomes \& DeBard, 2004; Howe \& Strauss, 2003). The sheer size of this generation of students, coupled with their "upbeat, highachieving, team-playing, and civic minded reputation" (Howe \& Strauss, 2003, p. 22), has"important implications for how colleges and universities develop programs and policies during the initial decades of the twenty-first century" (Coomes \& DeBard, 2004, p. 12). As such, it has never been more critical for higher education professionals to collect baseline data from students and to understand them within the larger framework of trends over time at both the national and institutional levels.

\section{Purpose}

The purpose of this article is to use institutional data collected from 30 years 
of CIRP Freshman Survey administration to provide an empirical portrait of critical trends and emerging issues among the student population entering the university directly from high school. These data are used to create a student profile to educate internal and external constituents about the backgrounds, needs, and interests of the incoming student population. Further, these data are used to identify changes over time and generational shifts in entering student cohorts that may mirror national trends or indicate the rise of generational influences that are unique to one institutional context.

As such, the following questions serve to ground the current study:

1. What are the characteristics of the current cohort of students entering the university in the following areas, adapted from Hansen and Denzine (2000) in their typology of student information: (a) demographic characteristics, (b) high school experiences, (c) academic preparation and degree aspirations, (d) expectations for college, (e) personal skills and abilities, (f) attitudes and values, and (g) career interests?

2. Have responses to the CIRP Freshman Survey over the past 30 years revealed significant shifts in students' perspectives and profiles in each of those seven areas?

\section{Methodology}

\section{Survey and Sample}

The data for this analysis were collected by administering the CIRP Freshman Survey ${ }^{1}$ to all students matriculating to the University of California, Los Angeles directly from high school during summer orientation from 1976 to 2006. ${ }^{2}$ The Freshman Survey is a paper instrument ranging from four to six pages in length that "is designed to elicit a wide range of biographic and demographic data, as well as data on the student's high school background, career plans, educational aspirations, financial arrangements, high school activities, and current attitudes" (Astin, Oseguera, Sax, \& Korn, 2002, p. 176). The content of the instrument remains consistent in thematic emphasis, but the wording of items is modified annually to maintain the relevancy of the survey and "to meet changing information and research needs" in higher education (p. 176). However, most critical to the current analysis is the protection of a core block of survey items that remain virtually identical from year to year, which allows for the "comparability of information..., which is required for assessing trends" and contrasting students' responses across entering cohorts and student generations (p. 176).

Although freshman orientation is not a requirement at UCLA, currently 95\% of all new students matriculating to UCLA directly from high school (i.e., not transfer students) attend Freshman Orientation. All of these students receive a copy of the survey and are invited to complete it. The institution administration

\footnotetext{
${ }^{1}$ The CIRP Freshman Survey has also been known as the Student Information Form over its 40-year history.

2 The survey was not administered at UCLA in 1993.
} 
method over the past 30 years has ranged from a proctored setting to dissemination in the orientation packets and providing multiple opportunities to turn in the completed survey throughout the orientation session. UCLA institutional researchers and orientation staff have collaborated to give the survey dedicated space on the orientation agenda and have sustained their commitment to administer this survey annually for all but one year (1993) in the past 3 decades.

Once a commitment to continued annual administration and the assessment of institutional trends had been established in 1980, survey response rates were calculated annually and analyzed over time. Figure 1 shows the trends with respect to CIRP Freshman Survey response rates at UCLA from 1980 to 2006. These statistics indicate that response rates have ranged from a low of $39 \%(\mathrm{~N}=1,608)$ in 1982 to a high of $88 \%$ in both $1988(\mathrm{~N}=3,405)$ and $2006(\mathrm{~N}=4,228)$. An analysis of sample representativeness for each year is outside the scope of this article. However, the fact that the average response rate was over $65 \%$ during this time period and that response rates have remained over 50\% since 1985 suggest that these data are adequately representative of the target population.

\section{CIRP Response Rates 1980-2006}

(Mean Response Rate $=65 \%$ )

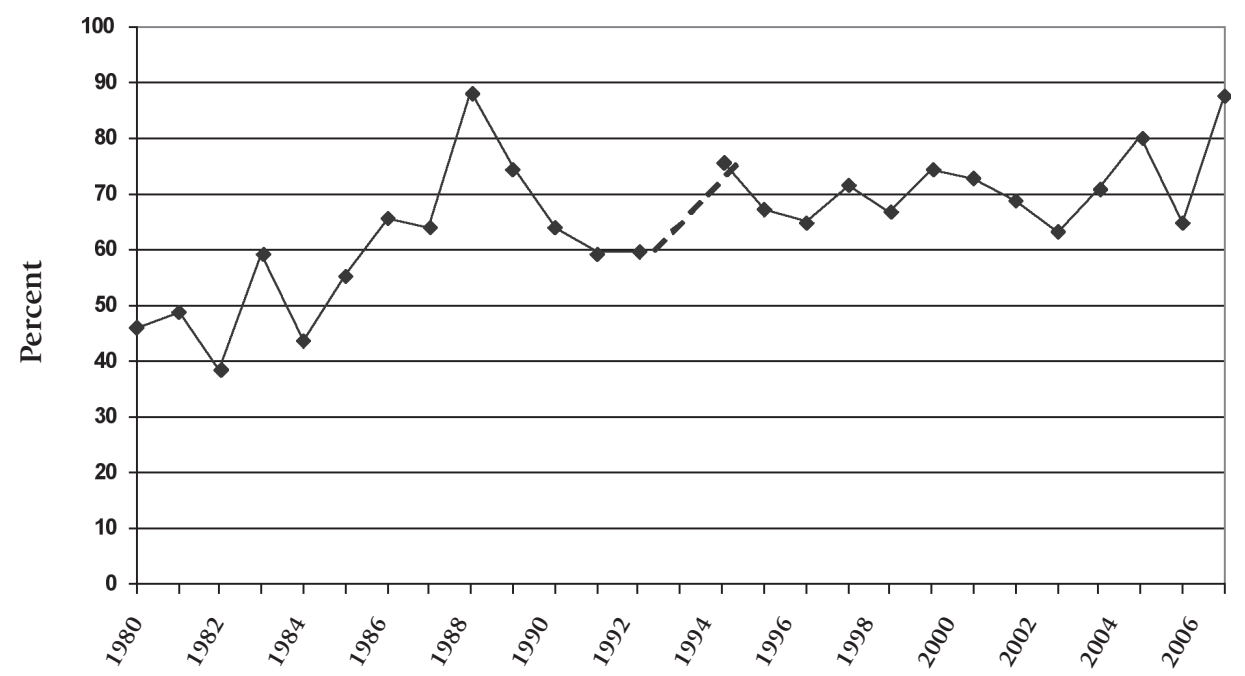

Data Source: Office of Analysis and Information Management APB Admissions Reports \& CIRP Trends File

\section{Limitations}

While this study advances our understanding of students at one institution by successfully creating a profile of students' characteristics, interests, needs, and 
aspirations, we would be remiss if we did not identify certain limitations of this study.

First is the fact that the data points in this study were collected via survey administration. While consistent student responses over time to many survey items suggested that the data were a reliable measure of the constructs of interest, student nonresponse and social desirability biases are likely to skew the data slightly.

As such, it is critical that we remember that these data often represented indirect measures of the variables of interest (e.g., students' perspectives and self-ratings) rather than direct measures.

Second, it is critical to understand that these data represent only the input of students who matriculated to college directly from high school (the target population of the CIRP Freshman Survey). As such, it does not represent the perspectives of new transfer students at UCLA or any other institution participating in the CIRP Freshman Survey. As the proportion of transfer students in each cohort of new students has increased to 40\% at UCLA (Office of Analysis and Information Management, 2006), the CIRP Freshman Survey has become less useful as a tool to represent the profile of all new students, although it remains a valuable tool for collecting information from our first-time freshmen. Therefore, it is important to appropriately identify the target population of the survey when reviewing and disseminating the findings.

\section{Analytical Methods}

Much like the wording of the survey items and their response options, summary statistics were generated with the same methods each year to facilitate comparisons across cohorts of students and the assessment of trends. Frequency distributions represented the primary means of data analysis for variables each year. More specifically, the statistics each year for categorical variables and interval variables with two or three response options represented the proportion of the sample that indicated each level of response. Trends for interval and ordinal variables with four or more response options were generally calculated by creating a reasonable threshold for reporting and then combining the percent of the sample that responded in those categories each year. Most often, these combined categories represented those respondents in the top few categories of the response range (e.g., over 10 hours per week, students reporting "some chance" or "a very good chance," respondents indicating "agree" or "agree strongly").

The values for each variable were then compared over time using two methods. The first was to list statistics from the same variable from two or more years in tabular format and calculating differences in percentage points, thus yielding a positive or negative change score (e.g., increase by 3 percentage points, a 12 percentage-point decrease). The second method was to create a figure that places the values over time for each variable along an $\mathrm{X}$-axis that represents a percent score and a Y-axis representing the year. These points were connected, thereby forming a trends line that created a visual depiction of variation over time for student responses to a survey item. 


\section{Results}

\section{Demographic Characteristics}

The demographic characteristics of UCLA's entering cohorts of first-time, full-time freshmen have, in many ways, shifted dramatically over the past 30 years. First, the proportion of women rose from being approximately equal to men in 1976 to a clear majority of 60\% in 2006 (see Table 1). When looking at this trend by year, we find that female representation was noticeably higher between 1977 and 1985 but then equalized between 1988 and 1992. In fact, in 1991 and 1992 men comprised the majority of respondents (51\% and 52\%, respectively). Women reclaimed the majority in 1994 (the survey was not administered at UCLA in 1993), reached a high of 61\% in 2001, and have sustained at least a 16 percentage-point gap over men since then. The increased representation of women over the past 30 years is also a national trend and women's enrollments are expected to continue at faster rates than men for at least the next decade (National Center for Education Statistics, 2006).

Another significant shift relates to the racial and ethnic composition of entering freshmen cohorts. The Higher Education Research Institute (HERI) altered this survey item over the years, in terms of the wording of the question (e.g., "Are you:"; "Please indicate the ethnic background of...") and the response options (e.g., in 2001 "American Indian" became "American Indian/Alaska Native"). These changes, which included the addition of new racial or ethnic categories, have undoubtedly impacted students' designation choices. HERI notes, for example, that the addition of five sub-categories that further specified the "Asian/ Asian American" category caused an increase in "the number of respondents that marked more than one category-regardless of what categories were marked" (HERI, 2006, p. 2). This survey has been consistent however, in allowing students the freedom to "mark all that apply." Further, it is critical to keep in mind the fact that changes in California legislation during the late 1990s (i.e., Proposition 209) put an end to the use of affirmative action policies in admissions practices, which had an impact on the racial distribution of applicants and admitted students to public colleges and universities in California campuses, including UCLA and other campuses in the UC system.

With these caveats in mind, the trends in this category revealed a dramatic 30 percentage-point decline in the proportion of students marking "White/Caucasian" (70\% in 1976 vs. $40 \%$ in 2006) and an equally striking increase in the proportion of students identifying as "Asian American" (18\% vs. 47\%, respectively). Over the same time span, the representation of students identifying as "Mexican American/ Chicano" increased by 6\%, while the percentage of students marking "Black/ African American" declined by $4 \%$. There has been relatively little change (less than $1 \%$ ) in the proportion of students marking "American Indian," "Puerto Rican American," or "Other."

In regards to citizenship, there was a 10-point decrease in the representation of non-U.S. citizens between 1982 and 2006. This was not a gradual decline, 
however, as there was a drop from $11 \%$ in 1986 to 3\% the following year. This sharp drop in students claiming foreign citizenship (8\%) may be a result of the Immigration Control and Reform Act of 1986, administered by the Immigration and Naturalization Service, which granted citizenship to millions of previously undocumented individuals. Meanwhile, between 1987 and 2006 there was a 9\% increase in the proportion of entering freshmen for whom English was not their first language, thus suggesting that native language has been an emerging area of diversity among UCLA students.

Religious preferences also shifted over the past 3 decades. In 1976, one third of the entering freshman cohort identified as "Protestant (Christian)," one quarter identified as "Roman Catholic" and one fifth did not identify with any religion. In 2006, the category with the largest proportion of students was "none" (32\%), followed by "Protestant (Christian)" (28\%), and "Roman Catholic" (21\%). Overall, the trends reveal declines in the proportion of students identifying as Jewish, Protestant, and Catholic, while there were increases in the "none" and "other" categories.

The two remaining trends, as presented in Table 1, addressed parental education and students' concerns about financing their college education. First, with regard to parental education, the proportion of students who had a college-educated parent increased over time such that in 2006, over half of all entering freshman reported having college-educated parents. When looking at this trend separately by the gender of the parent, however, stark differences emerged. The proportion of students with a college-educated mother increased by $25 \%$ while the gain in college-educated fathers was only $5 \%$. So while the gap between the educational attainment of mothers and fathers has persisted over this period, it has been reduced from a 24\% gap in 1976 to just a 3\% difference in 2006. Perhaps related to the increase in parental education, the proportion of respondents with "major" concerns about their ability to fund their college education dropped slightly over time. In general, concerns about financing college remained relatively stable across the three response options ("none," "some," and "major").

TABLE 1

$\begin{array}{lrrr} & \mathbf{\%} \text { in } & \begin{array}{r}\text { \% in } \\ \mathbf{2 0 0 6}\end{array} & \begin{array}{r}\mathbf{\%} \\ \text { Change }\end{array} \\ \text { Demographics } & \mathbf{1 9 7 6} & & \\ \text { Gender } & & & -9.1 \\ \quad \text { Male } & 49.5 & 40.4 & 9.1 \\ \quad \text { Female } & 50.5 & 59.6 & \\ \text { Race \& Ethnicity (mark all that apply): } & & & -29.6 \\ \quad \text { White/Caucasian } & 69.8 & 40.2 & -3.8 \\ \text { Black/African American } & 5.7 & 1.9 & -0.2 \\ \text { American Indian } & 1.1 & 0.9 & 29.5 \\ \text { Asian American } & 17.6 & 47.1 & 2.4 \\ \text { Hawaiian/Pacific Islander } & \text { N/A } & 2.4 & 6.0 \\ \text { Mexican American/Chicano } & 4.7 & 10.7 & \end{array}$




\begin{tabular}{|c|c|c|c|}
\hline Demographics & $\begin{array}{c}\% \text { in } \\
1976\end{array}$ & $\begin{array}{c}\% \text { in } \\
2006\end{array}$ & $\begin{array}{r}\% \\
\text { Change }\end{array}$ \\
\hline Puerto Rican American & 0.1 & 0.4 & 0.3 \\
\hline Other Latino & $\mathrm{N} / \mathrm{A}$ & 3.4 & 3.4 \\
\hline Other & 4.5 & 4.6 & 0.1 \\
\hline \multicolumn{4}{|l|}{ Citizenship } \\
\hline Not a US Citizen & $13.0^{\mathrm{a}}$ & 3.2 & -9.8 \\
\hline \multicolumn{4}{|l|}{ Native Language } \\
\hline English is not a native language & $18.8^{b}$ & 27.9 & 9.1 \\
\hline \multicolumn{4}{|l|}{ Religious Preference } \\
\hline Protestant (Christian) & 33.3 & 28.4 & -4.9 \\
\hline Roman Catholic & 24.6 & 20.8 & -3.8 \\
\hline Jewish & 14.5 & 5.5 & -9.0 \\
\hline Other & 7.3 & 12.9 & 5.6 \\
\hline None & 20.3 & 32.4 & 12.1 \\
\hline \multicolumn{4}{|l|}{ Parental Education } \\
\hline Father has at least a bachelor's degree & 55.8 & 60.4 & 4.6 \\
\hline Mother has at least a bachelor's degree & 32.1 & 56.9 & 24.8 \\
\hline \multicolumn{4}{|l|}{ Concerns About Financing College } \\
\hline None (I am confident that I will have sufficient funds) & 34.0 & 32.3 & -1.7 \\
\hline Some (but I probably will have enough funds) & 52.0 & 57.7 & 5.7 \\
\hline $\begin{array}{l}\text { Major (not sure I will have enough funds to } \\
\text { complete college) }\end{array}$ & 13.9 & 10.0 & -3.9 \\
\hline
\end{tabular}

${ }^{\mathrm{a}}$ asked in $1982,{ }^{\mathrm{b}}$ asked in 1987

\section{High School Experiences}

While incoming students have a myriad of high school experiences, 28 of which are available using CIRP Freshman Survey trends data, we focused on three of the experiences referenced by Hansen and Denzine (2000) that showed the most significant shifts over time: alcohol consumption, experiences working for pay, and students' experiences with service learning or volunteerism (see Figure 2). When asked in 1978 to indicate whether they had consumed beer in the year prior to entering college, over half of the responding students (52\%) indicated that they had, while only $28 \%$ of students entering in 2006 reported this. The most dramatic decrease in these numbers occurred between 1987 and 1992, when the proportion of students indicating that they drank beer dropped from its all-time high of $61 \%$ (1987) to only 33\% (1992). 


\section{High School Experience}

(Percent reporting that they engaged in these activities during their last year of high school)

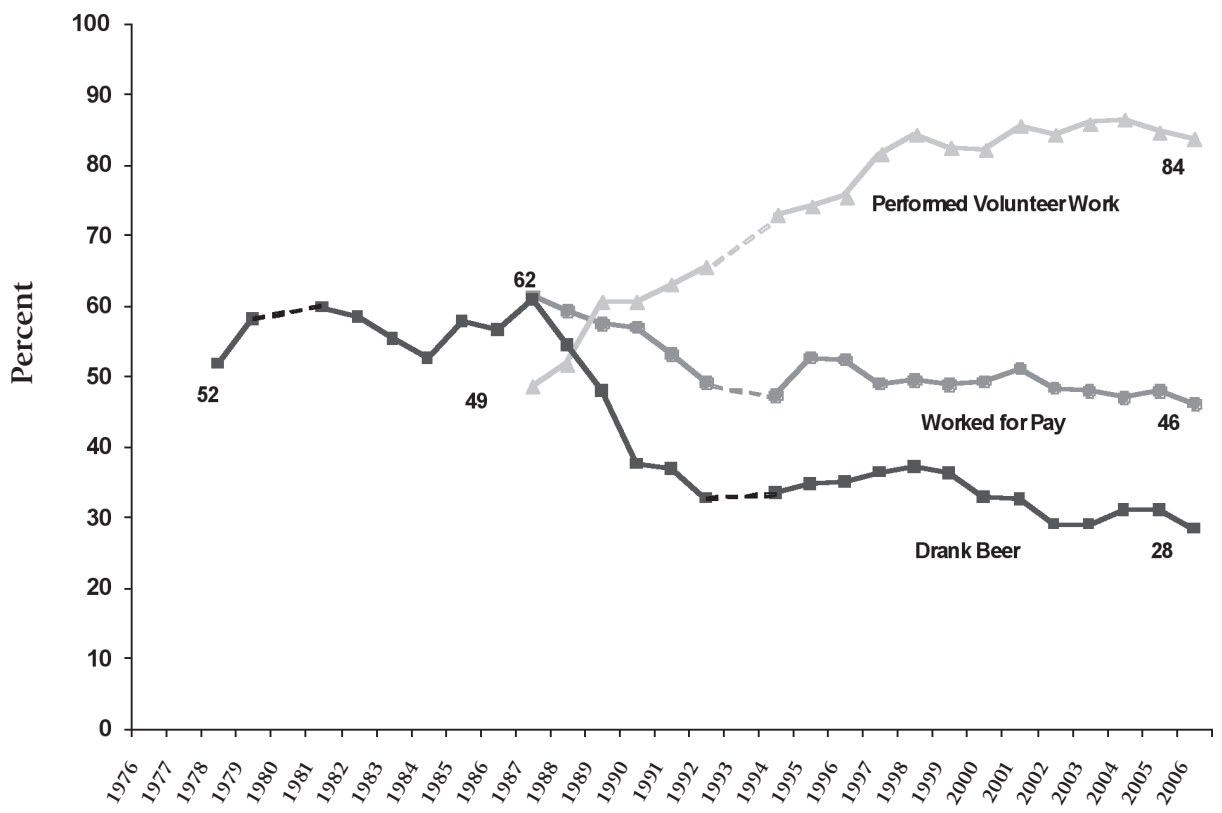

Another high school experience with noticeable changes was students' experiences working for pay in high school. In 1987, when asked to indicate how much time they spent during a typical week working for pay, $62 \%$ of respondents indicated that they had spent at least 1 hour per week working for pay. In comparison, less than half of respondents (46\%) reported doing so when asked in 2006 . This $16 \%$ decrease was noteworthy when considering that the number of students performing volunteer work for at least 1 hour during a typical week increased by $35 \%$ in that same time period, although it is unclear whether these trends are related. In 1987, approximately half of the respondents reported performing at least 1 hour of volunteer work weekly, while well over three quarters of all respondents reported having these volunteer commitments when asked in $2006(84 \%)$. 
In order to establish baseline data that would assist in understanding students' skill levels and preparation at entrance, the CIRP Freshman Survey included a number of measures addressing students' pre-college academic preparation and degree aspirations. For the purposes of this analysis, we focused our attention on four measures that could serve as exemplars of this category (see Table 2). One such measure of academic preparation is high school grade point average (GPA). In 1976, 23\% of respondents at UCLA reported a GPA equivalent to an A or A+, while nearly half of all respondents (45\%) in 2006 reported a similar GPA. This dramatic increase is interesting when compared to a related item, asking how much time during a typical week was spent studying and/or doing homework. While the number of students reporting higher GPAs increased by $23 \%$, the past 20 years have marked a $7 \%$ decline in the proportion of students who reported spending more than 6 hours per week studying or doing homework (66\% in 1987 vs. 59\% in 2006). These results mirror national trends that suggest high school grade inflation (Astin, Oseguera, Sax, \& Korn, 2002) among a new generation of grade-conscious, achievement-focus students (Howe \& Strauss, 2000).

TABLE 2

\section{Pre-College Academic Preparation \& Aspirations}

$\begin{array}{lrrr} & \mathbf{9} \text { in } & \mathbf{\%} \text { in } & \begin{array}{r}\text { \% } \\ \text { Change }\end{array} \\ & \mathbf{1 9 7 6} & \mathbf{2 0 0 6} & 22.5 \\ \text { High School GPA (A or A+) } & 22.9 & 45.4 & \\ \text { High School Coursework } & & & 2.5 \\ \text { English (4 years) } & 97.0^{\text {a }} & 99.5 & 3.9 \\ \text { Mathematics (3 years) } & 95.6^{\text {a }} & 99.5 & 1.4 \\ \text { Foreign language (2 years) } & 96.6^{\text {a }} & 98.0 & 11.3 \\ \text { Physical science (2 years) } & 60.7^{\text {a }} & 72.0 & 27.3 \\ \text { Biological science (2 years) } & 29.2^{\text {a }} & 56.5 & 0.3 \\ \text { History/American government (1 year) } & 99.1^{\text {a }} & 99.4 & -6.7 \\ \text { Computer science (1/2 year) } & 45.1^{\text {a }} & 38.4 & 44.5 \\ \text { Arts and/or music (1 year) } & 46.9^{\text {a }} & 91.4 & -7.2 \\ \text { Studying or Doing Homework (6 or more hours per week) } & 65.9^{\mathrm{b}} & 58.7 & \\ \text { Highest Academic Degree Planned } & & & -0.6 \\ \text { Less than a Bachelor's } & 0.9 & 0.3 & -7.0 \\ \text { Bachelor's (B.A.,B.S., etc.) } & 15.7 & 8.7 & 3.8 \\ \text { Master's degree (M.A.,M.S., etc.) } & 33.2 & 37.0 & 6.9 \\ \text { Ph.D. or Ed.D } & 17.8 & 24.7 & 2.4 \\ \text { M.D., D.D.S., D.V.M. or D.O. } & 19.1 & 21.5 & -4.5 \\ \text { LL.B. or J.D. (law) } & 11.6 & 7.1 & -0.9 \\ \text { Other } & 1.7 & 0.8 & \end{array}$

${ }^{\mathrm{a}}$ asked in $1984,{ }^{\mathrm{b}}$ asked in 1987 
In addition to information about study time and high school GPA, students were asked to indicate which courses they had completed in an effort to determine whether they had met or exceeded the high school coursework recommendations. There was relatively little change in the proportion of students reporting the completion of courses in English, mathematics, foreign language, and history/ American government. Over the past 20 years, however, the percentage of respondents taking both physical and biological sciences increased substantially. The proportion of students who met or exceeded 2 years of physical science increased from $61 \%$ in 1984 to $72 \%$ in 2006, representing an overall increase of $11 \%$. This increase was even greater in the biological sciences, as there was a $27 \%$ increase between 1984 (29\%) and 2006 (57\%). The proportion of respondents completing at least one-half year of computer science, however, dropped by nearly $7 \%$ between 1984 (45\%) and 2006 (38\%). The most startling shift in the reporting of coursework, though, was seen in the proportion of students who have met or exceeded the recommendation of taking 1 year of arts and/or music in high school. This number nearly doubled between 1987 and 2006, increasing by 45\% (47\% in 1987 vs. $91 \%$ in 2006). This dramatic increase in arts and/or music coursework experience may be attributable to a change in UC visual and performing arts requirements around that time, which required this type of coursework of incoming students.

In terms of degree aspirations, the trends revealed only slight changes in students' overall degree goals. The number of students aspiring to attain only a bachelor's degree (B.A., B.S., etc.) dropped by $7 \%$ in the last 30 years as a result of an upward trend of students planning to attain post-graduate degrees (including a master's degree, Ph.D., Ed.D., M.D., D.D.S., D.V.M., or D.O.). Interest in these post-graduate degrees has increased by $13 \%$ since the 1970 s.

\section{Expectations for College}

The CIRP Freshman Survey assessed students' expectations for college, asking participants to rate the likelihood of certain events occurring during their time in college. While Hansen and Denzine (2000) referenced more general areas of student expectations, including the need for support services, attitudes toward college, and readiness and motivation for doing college work, we focused more specifically on those expectations on the CIRP Freshman Survey, including students' potential to be satisfied with college, make at least a " $\mathrm{B}$ " average, work to help pay for college expenses, change major field, and seek personal counseling (see Figure 3). 


\section{Expectations for College}

(Percent estimating that the chances of doing the following in college were "very good")

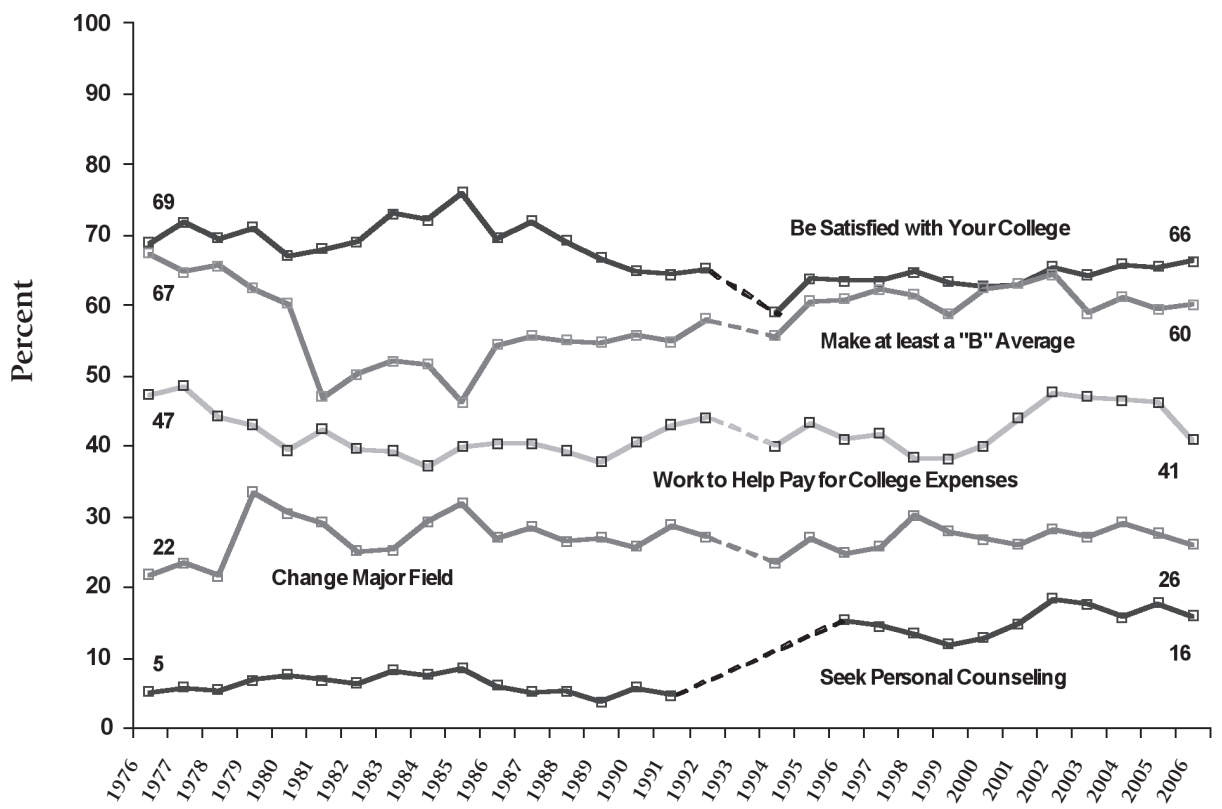

Overall, students' expectations of college in these five areas changed only slightly. We saw a 3\% drop in students who estimated that their chances of being satisfied with their choice of college was "very good," although the majority of students still expected to be satisfied with their choice (69\% in 1976 vs. 66\% in 2006). Respondents were particularly optimistic in 1985, when this proportion reached an all-time high of $76 \%$. Students' confidence in being able to make at least a "B" average also dipped slightly, dropping nearly 7\% in the last 30 years. Students' perceptions of their ability to make at least a " $\mathrm{B}$ " average recovered from a low in 1985 of $46 \%$, increasing almost 14\% to the 2006 level of $60 \%$.

The proportion of students estimating that there was a "very good" chance they would work to help pay for college expenses fluctuated fairly consistently over this 30-year span. In 1976, 47\% of respondents expected to work, which is only slightly greater than the $41 \%$ who had this expectation in 2006. There was a slight rise in the percentage of students who felt that chances were "very good" that they would work between 1999 (38\%) and 2003 (48\%), but there was a downward trend after that point.

In terms of students' academic plans, there was a slight increase of $4 \%$ over the past 30 years in the proportion of students who felt there was a "very good" chance 
that they would change their major field while at UCLA. In 1976, 22\% of respondents anticipated making this change while in college, which is not drastically different than the $26 \%$ that reported this in 2006. Overall, this trend line remained fairly steady over the 30 -year span, with one exception. Notably, the proportion of students anticipating a change in major jumped nearly $11 \%$ between 1978 and 1979 , from $22 \%$ to $33 \%$.

The proportion of students who anticipated seeking personal counseling while in college has also increased over the last 30 years. While only $5 \%$ of the respondents in 1976 anticipated that their chances of seeking counseling were "very good," this applied to $16 \%$ of respondents in 2006 . When examining the trends further, we found that there was a 3\% decline in the expectation of seeking personal counseling between 1985 and 1986, while there was a simultaneous 3\% increase in the proportion of students who rated themselves "above average" or "top 10\%" in both emotional health and social self-confidence. The greatest jump in the expectation to seek counseling occurred between the 1991 and 1997 administrations of the survey (increase of 10\%), although this question was not asked between 1992 and 1996. It remains unclear whether students' need for personal counseling has increased over time or if this trend is reflecting an increase in students' willingness to report this expectation. In either event, these data represent a call to us to make counseling services more readily available to our new student population.

\section{Personal Skills and Abilities}

There were five categories outlined in Hansen \& Denzine (2000) that address students' personal skills and abilities: psychosocial development, cognitive and structural development, multicultural competence, leadership experience and interest, and computer literacy. Although these measures, particularly the first three, are best measured qualitatively, the CIRP Freshman Survey did contain some items that began to address these areas. The items were mainly in the form of self-ratings where students were asked to rate their own abilities in comparison to the average person of his or her age (see Table 3).

TABLE 3

\begin{tabular}{lccr} 
Personal Skills \& Abilities & $\begin{array}{c}\text { \% in } \\
\mathbf{1 9 7 6}\end{array}$ & $\begin{array}{r}\text { \% in } \\
\mathbf{2 0 0 6}\end{array}$ & $\begin{array}{r}\mathbf{\%} \\
\text { Change }\end{array}$ \\
\hline $\begin{array}{l}\text { Psychosocial * } \\
\quad \text { Self confidence (social) }\end{array}$ & & & \\
$\begin{array}{l}\text { Cognitive and Structural * } \\
\text { Self confidence (intellectual) }\end{array}$ & 54.0 & 51.6 & -2.4 \\
$\quad$ Academic ability & 71.6 & 64.7 & -6.9 \\
$\quad$ Drive to achieve & 91.2 & 87.1 & -4.1 \\
$\quad$ Mathematical ability & 84.5 & 87.0 & 2.5 \\
& 61.0 & 63.0 & 2.0
\end{tabular}


Personal Skills \& Abilities

Cognitive and Structural (cont.)

Writing ability

Multicultural Competence

"Frequently" socialized with someone of another

racial/ethnic group

Leadership *

Leadership ability

Computer Literacy

"Frequently" used a personal computer
$\%$ in

1976

$\%$ in

2006

Change

57.7

52.0

$-5.7$

$82.7^{\mathrm{a}}$

81.9

$-0.8$

61.8

62.2

0.4

$25.1^{\mathrm{b}}$

$93.3^{c}$

68.2

a asked in $1992,{ }^{b}$ asked in $1985,{ }^{c}$ asked in 2005

* These measures reflect the percentage reporting that they were "above average" or "highest 10\%" in comparison with the average person of his/her age.

Six survey items were applicable to psychosocial, cognitive, and structural development: social self-confidence, intellectual self-confidence, academic ability, drive to achieve, mathematical ability, and writing ability. There was relatively little change in students' self-ratings on each of these items. More specifically, the proportion of respondents who rated themselves as "above average" or "highest $10 \% "$ in their level of social self-confidence hovered fairly steadily in the low to mid-50\% range between 1976 (54\%) and 2006 (52\%). Therefore, approximately half of the respondents in each entering class of freshmen over the past 30 years think highly of their social self-confidence in relation to their peers. The vast majority of respondents rated themselves as "above average" or "highest $10 \%$ " in their intellectual self-confidence, academic ability, and drive to achieve in 1976, and these figures remained fairly steady, with the largest decline occurring for the intellectual self-confidence item (though this decline was only 7\%).

The fact that these figures, particularly those related to cognitive development and academic achievement, remained high over the past 3 decades seems logical given that UCLA is a highly selective institution and its students are highly qualified. When examining the change in mathematical ability, this self-rating appears to have changed the least of the five with a $2 \%$ increase over the 30 years. Overall, slightly less than two thirds of respondents rated themselves highly in their mathematical ability in 1976 (61\%) and in 2006 (63\%), though the proportion of students with a high self-rating on this item began to increase in the mid-1980s and reached a high of $73 \%$ in 1992. A majority of respondents also rated themselves highly on their writing ability, though the proportion of students doing so was consistently smaller for this self-rating than the other four in this category. Fifty-eight percent of respondents were highly confident in their writing ability in 1976; this figure jumped to a high of 67\% in 1985 but has remained below 60\% since 1989, with the exception of $62 \%$ in 1998 .

The remaining areas in the personal skills and abilities category were multicultural competence, leadership, and computer literacy. There were few items that have appeared on the CIRP Freshman Survey that address multicultural 
competence, particularly not in the 1970s and 1980s, though an increasing number of these types of items began to appear in recent years. A possible precursor to developing multicultural competence is multicultural interaction. One survey item, "socialized with someone of another racial/ethnic group," addressed this kind of interaction. The overwhelming majority of students matriculating to UCLA directly from high school had previous experience interacting with someone from a different background. In 1992, when respondents at UCLA were first asked this question, $83 \%$ responded that they "frequently" socialized with someone of another race or ethnicity. This proportion rose slightly to $87 \%$ in the mid-1990s and declined to $82 \%$ in 2006 . Students' self-rated leadership ability remained steady between 1976 and 2006. The proportion of respondents rating themselves highly on this item ("above average" or "highest $10 \%$ ") was $62 \%$ at both time points and remained within 5\% of that figure during the intervening years. Finally, the most drastic shift within this category occurred with computer usage; only one quarter of respondents "frequently" used a computer in 1985 and this increased exponentially to $93 \%$ in 2005 , an increase of $68 \%$.

\section{Attitudes and Values}

There were a number of measures on the CIRP Freshman Survey that address students' attitudes and values concerning social issues and current events. In this analysis we have focused on four measures that not only address timely issues but also reflect the areas of greatest change with respect to students' opinions (see Figure 4). Students were asked to indicate their level of agreement with various opinions using a 4-point scale that ranged from "disagree strongly" to "agree strongly." This discussion focuses on the proportion of respondents who agreed "strongly" or "somewhat" with the item.

In the first example, students were asked to respond to the statement: "A national health care plan is needed to cover everybody's medical costs." The proportion of respondents who agreed with this statement shifted widely over the past 30 years. The most dramatic increase occurred between 1979-when a low of $46 \%$ agreed with this statement-and 1992-when agreement reached an all-time high of $72 \%$. Another somewhat related item asked students whether "wealthy people should pay a larger share of taxes than they do now." This item also reflected the view of the majority of respondents, although the proportion who agreed with the statement declined by $12 \%$ over the past 30 years ( $73 \%$ in 1976 vs. $61 \%$ in 2006 ).

Another item assessed students' level of optimism about the power an individual has in shaping the broader community. The trend line for this item revealed that a relatively small proportion of students feel pessimistic in this area. Only 42\% of respondents in 1976 agreed "strongly" or "somewhat" that "realistically, an individual can do little to bring about changes in our society." Over the subsequent 30 years, this proportion was cut in half; in 2006, only $21 \%$ agreed with this statement. In other words, $79 \%$ of respondents in 2006 disagreed "strongly" or "somewhat" with this statement, indicating an increased level of 


\section{Attitudes \& Values}

(Percent agreeing "strongly" or "somewhat")

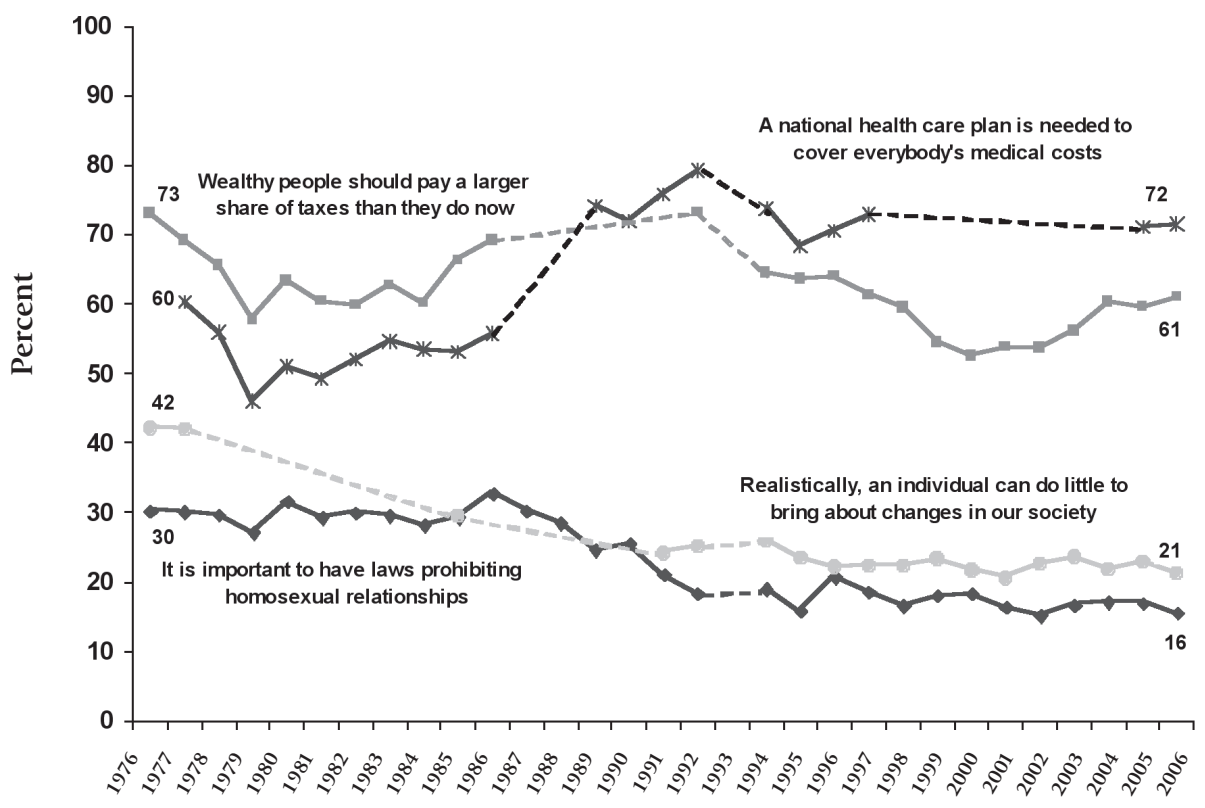

optimism about the power of the individual to influence society. As shown in Figure 4, much of the shift with this item occurred in the late 1970s and 1980s and opinions in this area remained relatively stable since the early 1990 s. The final measure of attitudes and values, which had a similar trajectory as the individual influence item, was the view that "it is important to have laws prohibiting homosexual relationships." Approximately one third (30\%) of respondents agreed with this statement in 1976, a proportion that remained fairly steady until 1986 when it reached its peak at $33 \%$ and then steadily declined to its all-time low of 16\% in 2006.

Examining these trends reveals that incoming freshmen shifted their opinions in various ways, but not necessarily in ways that were always consistent with one political party or another, although more often than not, the opinions examined for the purposes of this article indicated increasingly liberal-minded cohorts of entering freshmen. Another interesting pattern that was revealed by taking a 30-year perspective was that opinions in these areas have remained fairly consistent over the past decade. The major fluctuations in agreement with these opinions occurred prior to the 1990 s. 


\section{Career Interests}

The final category in Hansen and Denzine's (2000) framework was career interests. Out of an aggregated list of 20 career options, we focused our attention on the four most popular careers (Figure 5). In 2006, for example, these four career categories (undecided-22\%, doctor-19\%, business-12\%, and lawyer-7\%) reflected the interests of $60 \%$ of UCLA's respondents. The trend lines for each of these categories revealed an increase in the proportion of students who, as entering freshmen, were undecided about their future careers or were interested in pursuing a career in business. Interest in being a lawyer declined while interest in the medical field remained fairly steady with the exception of a peak in interest in the early to mid-1990s. It is uncertain how indicative these initial interests were of students' final career choices; however, this did provide helpful information regarding the changing interests and, perhaps, values of incoming freshmen. Further, since career interests were also reflected in students' choice of major field, this information can assist in anticipating which majors will be highly impacted and, in the case of "undecided" students, the need for career exploration resources and services.

\section{FIGURE 5}

\section{Career Interests}

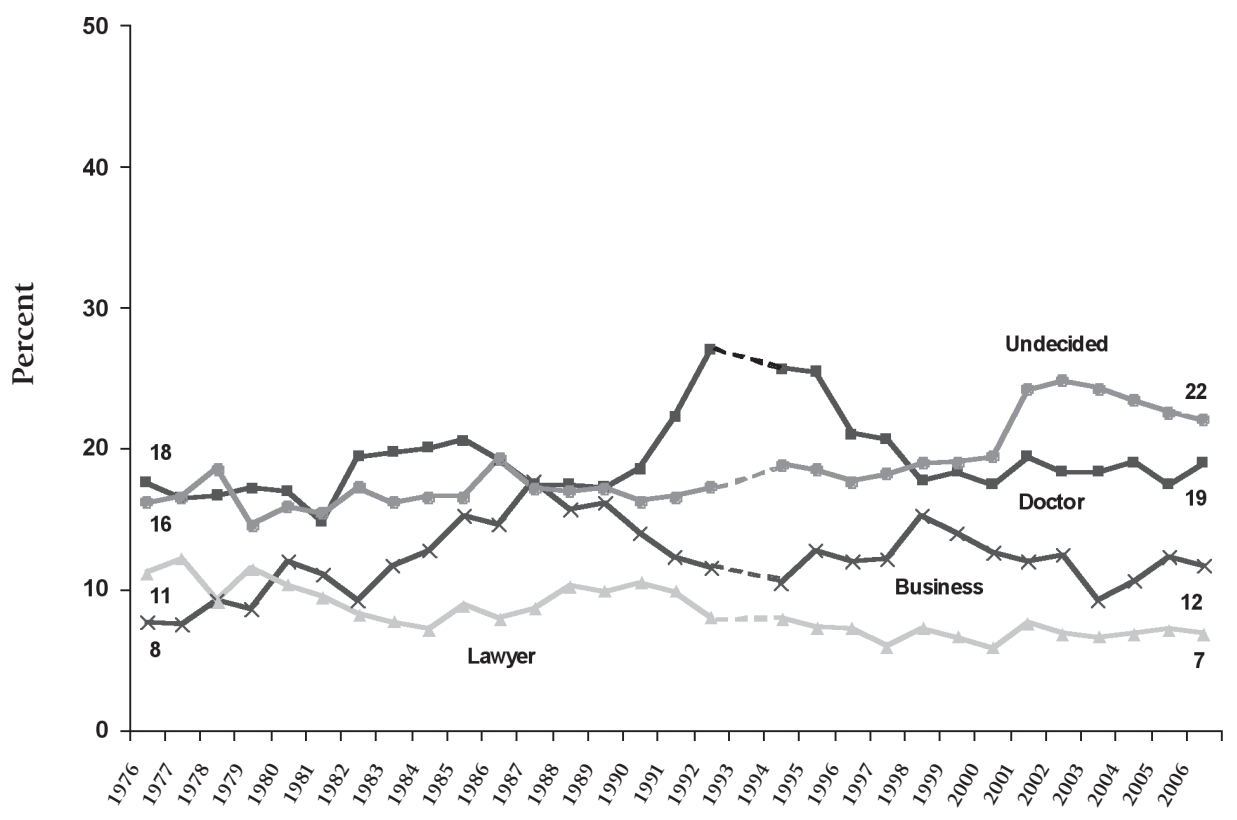




\section{Summary}

Overall, UCLA's cohorts of entering freshmen have become increasingly diverse over time, with respect to their gender, racial and ethnic background, religion, and native language. They are now more likely to have college-educated parents and an increasing proportion plan to obtain a post-graduate degree. Although an overwhelming proportion of UCLA's freshmen report high levels of self-confidence, particularly in the academic and leadership domains, institutional programming and attention could be directed toward the comparatively lower proportions of students who are as confident in the psychosocial areas examined. The trends in students' drive to achieve, volunteering habits, and in their attitudes and values, such as their optimism about the power an individual has to create changes in society, provide some support for the hypothesis that the "Millennial" students are upbeat, high-achieving, and civic-minded. The results also revealed an increase, among recent cohorts, in the expectation to seek personal counseling while in college and in the proportion of students who are undecided about their future career. While these two trends currently reflect less than one quarter of entering freshmen, an increased level of attention to the psychological and career counseling available to these students may be warranted, given the direction they have taken in recent years. In addition to these areas where many changes can be seen over time, the trends in students' expectations for college (with the exception of the expectation to "seek personal counseling") were among the most stable trends examined. The proportion of students concerned about financing college has also remained relatively stable over time.

This analysis has revealed some of the key changes that UCLA's cohorts of entering freshmen have exhibited over the past 30 years, as well as some of the areas where students have remained fairly static. Although the results and the direction of the trends discussed in this article are specific to UCLA, this approach can be taken on other campuses with attention to the key areas of interest specific to that context. A benefit of taking this long-term approach is that we can better understand how the characteristics and needs of students have shifted over time, with the hope that this information can help us anticipate their future needs and respond proactively with our institutional policies and practices. Now that these critical trends have been established, the next step is to better understand the reasons behind these shifts by comparing these results with other sources of institutional and national data.

\section{References}

Astin, A. W. (2003). Studying how college affects students: A personal history of the CIRP. About Campus, 8(3), 21-28.

Astin, A. W., Oseguera, L., Sax L. J., \& Korn, W. S. (2002). The American freshman: Thirty-five year trends. Los Angeles: Higher Education Research Institute, UCLA. Coomes, M. D., \& DeBard, R. (2004). A generational approach to understanding students. In M. D. Coomes \& R. DeBard (Eds.), Serving the millenial generation: New directions for student services, 106 (pp. 5-16). San Francisco: Jossey-Bass. 
Crissman, J. L., \& Upcraft, M. L. (2001). Assessing first-year programs. In J. H. Schuh, M. L. Upcraft, \& Associates (Eds.), Assessment practice in student affairs: An applications manual, (pp. 261-274). San Francisco: Jossey-Bass.

Hanson, G. R., \& Denzine, G.M. (2000). Student affairs research: The work we do. New Directions for Institutional Research, 108, 5-17.

Higher Education Research Institute. (2006). CIRP trends report 1971-2006: Resources. Los Angeles: Higher Education Research Institute, UCLA.

Howe, N., \& Strauss, W. (2000). Millenials rising: The next great generation. New York: Vintage Books.

Keup, J. R. (2004). What's so special about assessment in the first year of college? Assessment Update, 16(2), 8-10.

Keup, J. R., \& Kinzie, J. (2007). A national portrait of first-year students. In M. S. Hunter, B. McCalla-Wriggins, \& E. R. White (Eds.), Academic advising: New insights for teaching and learning in the first year (Monograph No. 46 [National Resource Center]; Monograph no. 14 [National Academic Advising Association]) (pp. 5-17). Columbia, SC: University of South Carolina, National Resource Center for The First-Year Experience and Students in Transition.

National Center for Education Statistics. (2006). Participation in education:

Undergraduate education. U.S. Department of Education. Washington, DC:

U.S. Government Printing Office. Retrieved from: http://nces.ed.gov/ programs/coe/2007/section1/indicator08.asp

Office of Analysis and Information Management (2006). Undergraduate profile: Fall 2006. Available from Office of Analysis and Information Management Web site, http://www.aim.ucla.edu/home/PROFILE_FALL2006.pdf

Pryor, J. H., Hurtado, S., Saenz, V. B., Santos, J. L., \& Korn, W. S. (2007). The American freshman: Forty year trends. Los Angeles: Higher Education Research Institute, UCLA.

Pryor, J. H., Hurtado, S., Saenz, V. B., Korn, J. S., Santos, J. L., \& Korn, W. S. (2006). The American freshman: National norms for fall 2006. Los Angeles: Higher Education Research Institute, UCLA.

Strauss, W., \& Howe, N. (1991). Generations: The history of America's future, 1584-2069. New York: Morrow.

Swing, R. L. (2004). What's so special about assessment in the first year of college? Assessment Update, 16(2), 1-4.

Upcraft, M. L. (2005). Assessing the first year of college. In M. L. Upcraft, J. H. Gardner, B. O. Barefoot, \& Associates (Eds.), Challenging and supporting the first-year student (pp. 469-485). San Francisco: Jossey-Bass. 